\title{
Licofelone in osteoarthritis: is this the awaited drug? a systematic review
}

\author{
Vinod Kumar P.* \\ Department of Pharmacology, Amala Institute of Medical Sciences, Thrissur, Kerala, India
}

Received: 09 March 2021

Revised: 11 April 2021

Accepted: 12 April 2021

*Correspondence:

Dr. Vinod Kumar P.,

Email: pvk1471@gmail.com

Copyright: $($ ) the author(s), publisher and licensee Medip Academy. This is an open-access article distributed under the terms of the Creative Commons Attribution Non-Commercial License, which permits unrestricted non-commercial use, distribution, and reproduction in any medium, provided the original work is properly cited.

\begin{abstract}
Osteoarthritis is a progressive joint disease associated with aging in elderly is, characterized by pain, inflammation, and difficulty in movement. The pathways involved in the progression of this disease remain unclear. The mediators, eicosanoids and leukotrienes are produced by COX-1/COX-2 or 5-LOX. Physicians have always used nonsteroidal anti-inflammatory drugs to treat the pain associated with osteoarthritis. A competitive inhibitor of LOX-5 and COX-2 that has both analgesic and anti-inflammatory activity is licofelone; one of the most promising candidates for the treatment of osteoarthritis is under clinical trial in treatment. A significant reduction in cartilage volume was displayed. A significant improvement over baseline on the WOMAC index and GI tolerance was also observed. Improving the symptoms related pain sensation with a happier life. With new strategies in OA, new methods to target pain, inflammation and movement restrictions would be the ultimate goal in patient satisfaction for the future. Licofelone was found to be effective compared to NSAIDs or coxibs in the treatment of OA. Does this mean this could be the answer?
\end{abstract}

Keywords: Osteoarthritis, NSAIDs, COX/5-LOX dual inhibitors, Licofelone

\section{INTRODUCTION}

Osteoarthritis, an age-related joint disorder, is a progressive illness associated with joint pain, inflammation and inability to move the joints (Figure 1), is pro-inflammatory, and progresses with age. ${ }^{1,2}$ LopezOtin et al planned nine distinctive features of aging, supports the fact that chronic inflammation in aging and age-related conditions suggests inflammation to be a crucial link between aging and OA (Figure 2). ${ }^{3}$

The features in the progression of $\mathrm{OA}$ is still not clear and many factors like cytokines, prostaglandins (PGs), and leukotrienes (LTs), effect on the cartilage chondrocyte may be associated. ${ }^{4,5}$ PGs and LTs are known to cause joint damage, pain, or swelling if OA is severe, where the senescence-associated secretory phenotype (SASP) maybe a promoting factor.

Eicosanoids are arachidonate-derived lipid mediators, the prostanoids (PGs and thromboxanes) and LTs; generate the COX-1/COX-2 or 5-LOX enzymes. Leukotrienes are the most potent mediators of inflammation with their role in arthritic diseases, including osteoarthritis. Osteoblasts synthesize LTs. Higher levels of LTB4 and PGs have been reported in the joints of the patients with $\mathrm{OA}$ and LTB4 is thought to mediate the cartilage damage. ${ }^{6,7}$ Enzymes like cyclooxygenase (COX) and lipoxygenase (LOX), with cytochrome P450 (CYP) pathways, are associated with the arachidonic acid (ARA) pathway. ${ }^{8-11}$ The higher levels of leukotrineB4 (LTB4) and prostaglandins (PGs) have been reported in the joints of 
the patients with OA wherein LTB4 is thought to mediate the cartilage damage. ${ }^{12,13}$ The role of eicosanoids in the pathophysiology of arthritic diseases, including osteoarthritis, was revealed in recent studies. In rheumatoid arthritis patients elevated lipids in the synovial fluid seem to correlate with the phospholipids, PGE, and LTB4 with OA patients. ${ }^{14-16}$

High levels of serum or synovial fluid concentration of TNF- $\alpha$, IL-1 $\beta$, IL-6, IL-15, IL-17, IL-18, and NO in patients of OA were reported in studies. Prostacyclin (PGI2) and PGE2 play an important role by modulating the gastrointestinal mucosal defence and repair in the gastrointestinal tract. ${ }^{17,18} \mathrm{LOX} / \mathrm{COX}$ inhibitors block both the COX-1 and COX-2 pathways and the 5-LOX metabolic pathway by inhibiting the formation of PGI2 and PGE2, contributing to acute inflammation. ${ }^{19-21}$ NSAIDs inhibit the COX enzymes but have no anti-5LOX activity to prevent the formation of leukotrienes (LTs). Physicians have always trusted the use of nonsteroidal anti-inflammatory drugs (NSAIDs) for the treatment of OA. NSAIDs inhibit both COX-1 and COX2, or coxibs (e.g., rofecoxib, celecoxib), that selectively inhibit COX-2, reduce the levels of PGs, resulting in relief from pain and inflammation is often associated with damage to gastric mucosa which is severe or with complications of the cardiovascular system, with a known fact that the use of NSAID is limited due to of gastrointestinal adverse effects compared to coxibs. ${ }^{10,12-14}$

The most promising dual inhibitor developed so far is licofelone which competitively inhibits COX-1/COX-2 and 5-LOX enzymes having analgesic, antiinflammatory, antiplatelet effect and is currently under clinical evaluation for the treatment of OA. ${ }^{22,23}$ The combination of 5-LOX inhibitors or LT receptor antagonists with NSAIDs has reported benefits in not only relieving pain and inflammation but also preventing or reducing NSAID-induced gastric damage. This has lead to the concept of dual inhibition (i.e., COX and 5LOX inhibition) emerging as an alternative and safe therapy for enhanced analgesic and anti-inflammatory effect with little or no gastric mucosal damage. ${ }^{24}$ An estimated cost of around $2 \%$ in developed countries is associated with osteoarthritis (OA) helping to reduce or stop its progression. ${ }^{25-28}$ Three COX/5-LOX dual inhibitors in the advanced stage of clinical development for $\mathrm{OA}$ are licofelone, flavocoxid and tepoxalin. Among these licofelone is a drug developed for humans, flavocoxid a medical food indicated for OA in humans and tepoxalin is approved for canines, each having a distinct mechanism of action that may affect safety and efficacy. Licofelone specifically inhibits the cyclooxygenase moieties of the COX enzymes as well as 5-LOX induction. The first dual inhibitor LOX-5 and COX-2, benoxaprofen, is no longer used due to liver toxicity another dual 5-LOX/COX inhibitor; flavocoxid is a USFDA-regulated prescription medical food for the clinical dietary management of the metabolic processes of OA also having antioxidant property. ${ }^{29,30} \mathrm{~A}$ promising candidate for the treatment of osteoarthritis is a competitive inhibitor of LOX-5 and COX-2 enzyme, licofelone, that has both analgesic and anti-inflammatory effects with initial studies indicating that licofelone (ML 3000); 2, 2-dimethyl-6(4-chlorophenyl)-7-phenyl-2, 3dihydro-1H-pyrrolizine5-yl-acetic acid was involved in phase III clinical trial displaying very good gastric safety, a positive effect on bone remodelling in osteoarthritis, reporting no adverse effects on the stomach. Licofelone has not yet been submitted for regulatory approval despite these promising results. ${ }^{31-33}$

\section{Literature search}

The keywords for identifying knee OA were licofelone osteoarthritis, OA in elderly, knee OA, (MeSH) or osteoarthritis, knee osteoarthritis, OA in elderly, COX-1, COX-2, lipoxygenase, 5-LOX, nonsteroidal antiinflammatory drugs, naproxen, celecoxib, dual inhibitors (PubMed). The highest impact factor general and internal medicine journals, highest impact factor rheumatology journals, British medical journal, British journal of pharmacology, osteoarthritis cartilage, annual review of medicine, arthritis and rheumatism, annals of rheumatic diseases, nature clinical practice rheumatology, arthritis research and therapy, advanced therapeutics, seminars in arthritis and rheumatism; osteoarthritis and cartilage, rheumatology (Oxford), drugs ageing, arthritis, clinical interventions in aging, current opinion in rheumatology; journal of rheumatology; lancet, current review musculoskeletal medicine, best practice and research in clinical rheumatology, F1000 research. Identifying journal articles with high methodological quality in journals with a high impact factor was searched.

\section{METHODS}

The elderly are associated with osteoarthritis, associated with the knees, hips, and other joints, giving the purpose of current investigation. The author independently searched words like osteoarthritis, osteoarthritis, OA in elderly, knee OA, cyclooxygenase, COX-1, COX-2, lipoxygenase, 5-LOX, nonsteroidal anti-inflammatory drugs, NSAID toxicity, naproxen, celecoxib, NSAID organ toxicity, arachidonic acid metabolism, osteoarthritis, and combinations across the databases and selected ten most relevant related articles to the over a period from 2002-2016, and summarized them.

Following international consensus regarding the core set of outcome measures for phase III clinical trials in OA, those participating in randomized control trials (RCTs) had to include at least self-reported pain and/or selfreported disability in the assessment. ${ }^{34}$ Pain in knee OA was measured by Western Ontario or McMaster universities osteoarthritis index (WOMAC pain subscale) or by a visual analog scale (VAS). The assessment for the patient-reported disability was done with WOMAC function subscale or by a short form 36 (SF-36). ${ }^{35-37}$ 
MRI and X-ray examinations were done at six months for MRI only for baseline and 12 and 24 months for X-ray. MRI was done to evaluate the changes in cartilage volume and $\mathrm{X}$-ray examination to measure the mean and minimum joint space width (JSW) in the medial compartment. Questionnaires regarding symptoms were noted and the data for intention to treat (ITT) was presented and according to the protocol (ATP).$^{38}$

Table 1: Summary of studies.

\begin{tabular}{|c|c|c|c|c|c|}
\hline Drug & Phase & Patient cohort & Clinical endpoint & Results & Reference \\
\hline $\begin{array}{l}\text { Licofelone } \\
\text { and } \\
\text { naproxen }\end{array}$ & $\begin{array}{l}\text { Phase } \\
\text { III }\end{array}$ & $\begin{array}{l}\text { In OA patients }(n=148) \text { for } \\
12 \text { weeks }\end{array}$ & $\begin{array}{l}30 \% \text { improvement } \\
\text { over baseline on the } \\
\text { WOMAC index }\end{array}$ & $\begin{array}{l}\text { An improvement over } \\
\text { baseline on the WOMAC } \\
\text { index }\end{array}$ & $31-33$ \\
\hline $\begin{array}{l}\text { Licofelone } \\
\text { and } \\
\text { naproxen }\end{array}$ & - & $\begin{array}{l}52 \text { week, double-blind study } \\
(\mathrm{n}=710) \text { patients with OA of } \\
\text { the knee. }\end{array}$ & $\begin{array}{l}\text { General and GI } \\
\text { tolerability }\end{array}$ & $\begin{array}{l}\text { Licofelone had a lower } \\
\text { incidence of hypertension } \\
\text { aggravation than naproxen. }\end{array}$ & $34,54,55$ \\
\hline $\begin{array}{l}\text { Licofelone } \\
\text { and } \\
\text { celicoxib }\end{array}$ & & $\begin{array}{l}\text { Patients }(n=148) \text { with OA } \\
12 \text {-week clinical study }\end{array}$ & $\begin{array}{l}\text { Symptomatic } \\
\text { osteoarthritis of the } \\
\text { knee }\end{array}$ & $\begin{array}{l}\text { Licofelone was as effective } \\
\text { as celecoxib, showed better } \\
\text { tolerability with a lower } \\
\text { incidence of adverse } \\
\text { events. }\end{array}$ & $31-33$ \\
\hline Licofelone & $\mathrm{RCT}$ & Knee OA (355 patients) & $\begin{array}{l}\text { Cartilage volume } \\
\text { and JSN assessed } \\
\text { by quantitative } \\
\text { MRI }\end{array}$ & $\begin{array}{l}\text { Significant reduction in } \\
\text { cartilage volume, JSN } \\
\text { unchanged }\end{array}$ & $34,58,59$ \\
\hline
\end{tabular}

JSN: joint space narrowing, WOMAC: Western Ontario and McMaster universities arthritis index, RCT: randomized control trial

\section{Inclusion criteria}

Inclusion criteria for current review were; matching of atleast one keyword, articles that included primary knee $\mathrm{OA}$ as an intervention group assessed clinically or radiological method, with or without meta-analysis of randomized controlled trials, phase 3 results, scientific journal search, articles displaying relief from symptoms and wellbeing of patients with knee related pain, a detailed description of the non-pharmacological and nonsurgical intervention and their full version, in English

\section{Exclusion criteria}

Inclusion criteria for current review were; papers with an experimental or control group composed of any animals, papers with participants that do not have a knee OA (healthy volunteers) or who have secondary knee OA (traumatic or post-surgical), papers with exclusively pharmacological or surgical interventions, any article in trials, any case reports, any books and papers presented at conferences, papers with subjects with other diseases, namely cancer, heart diseases, kidney diseases, neurological diseases, respiratory diseases, rheumatoid arthritis, gout arthritis, septic arthritis, or Paget's disease and papers included exclusively only with osteoarthritis in the hip, foot, shoulder, elbow, wrist, and/or fingers.

\section{RESULTS}

Total 148 patients who received either licofelone $(200 \mathrm{mg}$ bid) or naproxen (500 mg bid) for 12 weeks with OA, with the WOMAC index displaying a $30 \%$ improvement over baseline readings, the two groups responded with
$69 \%$ in the licofelone group $(\mathrm{N}=72)$ and $68 \%$ in the naproxen group $(\mathrm{N}=76) .{ }^{39-54}$ GI side effects of $14 \%$ and gastroduodenal ulcers developed in $1.5 \%$ with licofelone treated patients whom compared to $26 \%$ and $15 \%$ with naproxen was reported. ${ }^{55}$ In another study involving 148 patients the improvement in the mean WOMAC index with licofelone was $23.3 \mathrm{~mm}$ and with naproxen 21.5 mm. $13.9 \%$ (licofelone) and $26.3 \%$ (naproxen) patients reported GI adverse events. The WOMAC index of $69.4 \%$ with licofelone treated patients and $68.4 \%$ with naproxen was reported. ${ }^{55}$ In 710 patients with OA knee for 52 weeks, assessing the long-term safety and efficacy of licofelone in a dose of 100 or $200 \mathrm{mg}$ bid was compared with naproxen $500 \mathrm{mg}$ bid, licofelone showed similar efficacy to naproxen at fourth week in both doses and licofelone showing a better, general and GI tolerability than naproxen. GI ulcers, for $100 \mathrm{mg}$ bid dose of licofelone showed $0.14 \%$, and for $200 \mathrm{mg}$ bid dose $0.39 \%$ and naproxen $2.5 \%$ in phase III studies..$^{29,53-55}$

In a 52 week, multicentre, double-blind, phase III trial, tolerability and efficacy of licofelone compared with naproxen, the efficacy of licofelone $200 \mathrm{mg}$ was found to be similar to naproxen, showing superior tolerability of licofelone compared with naproxen. WOMAC pain score rates after 12 weeks of therapy displayed 77.9 and $76.4 \%$ in licofelone and naproxen respectively, that showed a more than $>30 \%$ improvement in score from baseline. ${ }^{56-58}$

A study that included 355 patients with knee OA that were studied to prove superiority of MRI over X-ray in a multicentre clinical trial, to explore the effects of licofelone as a disease modifying osteoarthritis drug in comparison with naproxen in patients with knee OA, using MRI and X-ray, receiving either licofelone $200 \mathrm{mg}$ 
twice daily or naproxen $500 \mathrm{mg}$ twice daily. After 12 and 24 months, licofelone markedly reduced the cartilage loss for intention to treat (ITT), while in joint space width (JSW), licofelone showed less reduction than naproxen, but did not reach significant levels. OA symptoms reduced equally with licofelone and naproxen, and licofelone significantly reduced cartilage volume over time, providing a protective effect in patients with knee OA. ${ }^{57-59}$

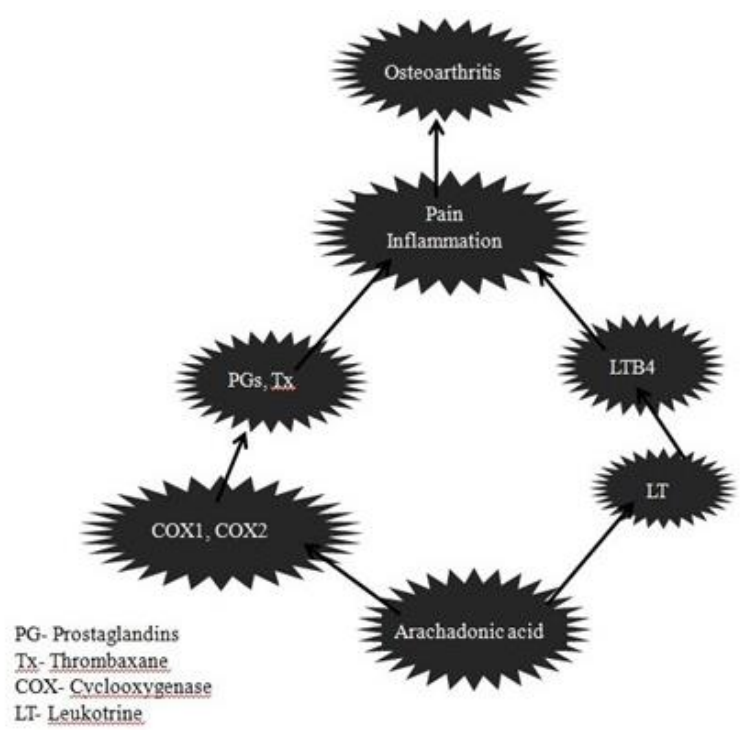

Figure 1: Pain pathway and OA.

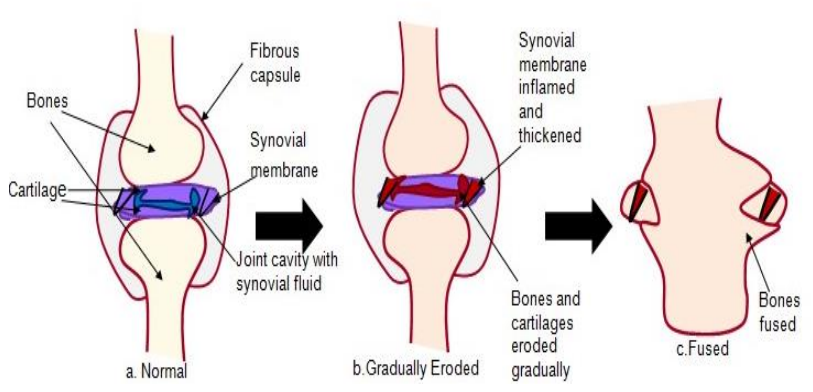

Figure 2: Progression of OA.

\section{DISCUSSION}

Only clinical studies in phase 3 , randomized control trial (RCT) with their results were looked and preclinical studies were ignored. The prevalence of arthritis with OA is high and is the most common disorder in the population. 1.3 to 1.75 million people is affected with $\mathrm{OA}$ in England and Wales, while every year, around 6 million new cases are diagnosed in France. This number is increasing year after year, especially in the elderly mainly associated with musculoskeletal disorders of physical and functional impairments, comprising medical intervention costs, premature mortality, and short-term disability, leaving an impact on the quality of life..$^{39-41}$ Details of study related to licofelone is very limited and reports are found only in a few reviews and press releases. ${ }^{42-43}$
The role played by eicosanoids in the pathophysiology of arthritic diseases, including osteoarthritis, has been revealed and the role of leukotriene-B4 (LTB4) synthesis and IL- $1 \beta$ by synovium in osteoarthritis. ${ }^{44-47}$ Cheng et al, 2004, suggested the PG-affected processes in OA are affected by other mediators like LTs. ${ }^{48}$ LTB 4 in osteoblasts stimulates and enhances the production of IL$1 \mathrm{C}$ and tumour necrosis factor- $\beta$ (TNF $\beta$ ). The synthesis of LTB4 and IL-1 $\beta$ was significantly increased by NSAIDs explaining how some NSAIDs accelerate the progression of clinical osteoarthritis. ${ }^{44,49-52}$

148 patients who received either licofelone (200 mg bid) or naproxen (500 mg bid) for 12 weeks with OA, with the WOMAC index displaying a 30\% improvement over baseline readings. Similar efficacy was observed in the two groups, with $69 \%$ responding in the licofelone group $(\mathrm{N}=72)$ and $68 \%$ in the naproxen group $(\mathrm{N}=76)$. Licofelone treated patients reported GI side effects of $14 \%$, in whom gastroduodenal ulcers developed in $1.5 \%$, compared with $26 \%$ and naproxen reported $15 \%$. Abdominal pain or discomfort was reported as the most common adverse effect with $4.2 \%$ of patients on licofelone compared to $7.9 \%$ on naproxen. ${ }^{55}$

A double-blind study in 710 patients with OA knee for 52 weeks assessing the long-term safety and efficacy of licofelone (100 or $200 \mathrm{mg}$ bid) was compared with naproxen (500 $\mathrm{mg}$ bid) of licofelone showed similar efficacy to naproxen at 4 th week in both doses. The efficacy of licofelone improved throughout the 52 weeks study. Licofelone showed better general and GI tolerability than naproxen. In phase III studies for GI ulcers, for $100 \mathrm{mg}$ bid dose of licofelone was $0.14 \%$, for $200 \mathrm{mg}$ bid dose $0.39 \%$ and naproxen $2.5 \% .^{29,53-55}$

In a study involving 148 patients with knee OA for 12 weeks who were treated with licofelone $200 \mathrm{mg}$ bid or naproxen $500 \mathrm{mg}$ bid, the efficacy was evaluated using the Western Ontario and McMaster Universities (WOMAC) Osteoarthritis Index, with a $30 \%$ improvement compared to baseline in responders, the mean WOMAC index with licofelone improvement was $23.3 \mathrm{~mm}$ and with naproxen $21.5 \mathrm{~mm}$. $69.4 \%$ with licofelone treated patients and $68.4 \%$ with naproxen was the WOMAC index. $13.9 \%$ (licofelone) and 26.3\% (naproxen) patients reported GI adverse events. ${ }^{55}$

In a 52-week, multicentre, double-blind, phase III trial, tolerability and efficacy of licofelone compared with naproxen, demonstrated that licofelone was effective as naproxen in osteoarthritis. ${ }^{56,57}$ Symptomatic knee OA, was defined as per guidelines of American college of rheumatology, in patients who had discontinued NSAID therapy 3-14 days before the first visit, were randomized to receive licofelone in a dose of either $100 \mathrm{mg}$ bid, 200 $\mathrm{mg}$ bid, or naproxen $500 \mathrm{mg}$ bid. The efficacy of licofelone $200 \mathrm{mg}$ was found to be similar to naproxen with results showing superior tolerability of licofelone compared with naproxen. ${ }^{58}$ 
The efficacy and tolerability of licofelone compared with selective COX-2 inhibitor celecoxib in patients with OA in a multicentre, randomized, double-blind, parallelgroup, phase III trial conducted over 12 weeks. ${ }^{57}$ Results indicated that treatment with licofelone $200 \mathrm{mg}$ twice daily was as effective as celecoxib $200 \mathrm{mg}$ once daily, with similarity in GI adverse effects in both groups, with licofelone reporting fewer incidences of peripheral edema than celecoxib.

The inhibition of COX alone the inhibition of both 5LOX and COX (i.e., COX-1 and COX-2) might counteract inflammatory vascular changes and leukocyte induction, resulting in more anti-inflammatory action and a better safety profile of the gastrointestinal tract compared to COX alone and a new anti-inflammatory drug could cover all the therapeutic needs in elderly patients that is the need of the hour having no genotoxic effects. ${ }^{29}$ LOX/COX inhibitors seem to positively affect cartilage metabolism, slowing the degenerative process of OA, reducing pain and pain-related disability. Results indicate the efficacy of licofelone therapy was as effective as naproxen. WOMAC pain score rates of 77.9 and $76.4 \%$ in the licofelone and naproxen respectively after 12 weeks of therapy, showed $>30 \%$ improvement in score from baseline was observed.

Gracia in 2004 revealed licofelone treatment was associated with a dose-dependent improvement in WOMAC pain scores from baseline and the efficacy of licofelone $200 \mathrm{mg}$ was similar to that of naproxen with 26, 39, and 52 weeks showing greater efficacy. Licofelone showed superior tolerability regarding GI adverse events, cardiovascular adverse events compared with naproxen, with lifelong treatment groups experiencing fewer adverse events than naproxen group with 100 and $200 \mathrm{mg}$. No clinically relevant variations in laboratory parameters or vital were found in the longterm licofelone therapy. ${ }^{31}$ Clinical data suggests licofelone was as effective as conventional NSAIDs or coxibs in improving the symptoms of OA, with the advantage of improved GI tolerability and with few or no incidence of peripheral edema, suggesting an alternative for OA patients for long term treatment. ${ }^{54-56}$

A study that included 355 patients with knee OA were studied to explore the effects of licofelone as a diseasemodifying osteoarthritis drug in comparison with naproxen in patients with knee OA, using MRI and X-ray examination in a randomized manner receiving either licofelone $200 \mathrm{mg}$ twice daily or naproxen $500 \mathrm{mg}$ twice daily in 2009. MRI and X-ay examinations were done at six months for MRI only for baseline and 12 and 24 months for X-ray. MRI was done to evaluate the changes in cartilage volume and $\mathrm{X}$-ray examination to measure the mean and minimum joint space width (JSW) in the medial compartment. Questionnaires regarding symptoms were noted, intention to treat (ITT) data was presented. At 12 and 24 months, licofelone markedly reduced the cartilage loss for ITT. In JSW, licofelone showed less reduction than naproxen, significance levels were not reached. OA symptoms reduced equally with licofelone and naproxen, but licofelone significantly reduced cartilage volume over time, providing a protective effect in patients with knee OA proving the superiority of MRI over X-ray in a multicentre clinical trial and for cell senescence, cell proliferation is not a requirement, that occurs after repetitive stress to tissues and cells. ${ }^{57-60}$ This may explain chondrocyte senescence detected in OA tissue where chronic repetitive loading is experienced and excessive loading associated with the development of OA and the meniscus, being a source of inflammatory mediator in the joint. Brophy et al reported that the proinflammatory cytokine IL- $1 \beta$ and the matrix-degrading enzymes were highly expressed in meniscal tissue isolated from young subjects ( $<40$ years old) than from older subjects $(>40)$. Further studies are needed to better understand its role in OA, leading to new interventions, targeting inflammation, and reducing pain and disability in older adults with $\mathrm{OA}$ and joint tissue destruction. ${ }^{61-63}$ Freund et al reported various inducers of cell senescence like senescence-associated secretory phenotype (SASP) that could be a promoting factor in age related pathologies like osteoarthritis, with increased levels of inflammatory mediators, and the mechanism includes DNA damage and activation of the p38 MAP kinase suggesting, patients who receive long-term treatment of NSAID, may be associated with a increased rate of OA progression..$^{52,64-70}$

\section{Current perspectives}

Clinical studies have demonstrated that licofelone; effectively treat $\mathrm{OA}$ and results are comparable to the conventional NSAIDs, naproxen, and diclofenac. It is well-tolerated with fewer side effects, suggesting that dual inhibition of COX and 5-LOX may reduce the undesirable GI side effects associated with NSAIDs. The new class of the LOX/COX inhibitors presents several beneficial and promising therapeutic effects that could be very important in the elderly. Based on pharmacological studies, it has been suggested that licofelone may be a disease-modifying drug. Licofelone could be a better alternative to NSAIDs and selective COX-2 inhibitors in treatment of OA, but future clinical studies are required to study the effects of the renal side effects of licofelone. Although it has been suggested that the rate of adverse events associated with licofelone may be comparable to selective COX-2 inhibitors with the possibility of less risk of cardiovascular and thromboembolic complications, there is no direct clinical evidence to support this, and further trials are needed. Whether these data are the reason why licofelone not progressed since its positive Phase III data is unclear.

\section{CONCLUSION}

Licofelone, a new class of anti-inflammatory agents is the need of the hour for the elderly, as traditional and more recent ones have failed in safety profile. Licofelone, 
would an ideal disease modifying drug with better tolerability and acceptability for its role in OA with a mechanism of action that may be associated with the inhibition of LTB4, that is responsible for damage of the structural changes of joints. The long-term improvement in a patient in combination with advanced disease modifying treatments for osteoarthritis (DMOADs), might lead to the development of personalized OA therapeutics. Larger clinical trials need to be done as there is inadequate of published data, especially in the elderly, which seems to be the main drawback/limitation. Licofelone is shown to be as effective as conventional NSAIDs or coxibs in the recovery of symptoms related $\mathrm{OA}$, so does this mean, it could be the answer for osteoarthritis therapy that are still unmet?

\section{Recommendations}

The main drawback of licofelone is lack of published data, regarding their clinical effectiveness and safety of COX/LOX dual inhibitors. Licofelone, is a competitive inhibitor of cyclooxygenase 1 and 2 (COX 1 and 2) and 5lipoxygenase (5- LOX), that possess both analgesic and anti-inflammatory properties with a positive effect on bone remodelling in osteoarthritis. Like conventional NSAIDs, the COX and 5-LOX dual inhibitors decrease the production of PGs with fewer general and GI side effects compared to NSAIDs. This could be an ideal disease modifying drug for arresting the pathophysiology of OA that enables better tolerability and acceptability.

\section{ACKNOWLEDGEMENTS}

Author is thankful to his guide, co-guide, colleagues and staff of the research centre for their contribution in current investigation.

\section{Funding: No funding sources \\ Conflict of interest: None declared \\ Ethical approval: Not required}

\section{REFERENCES}

1. Molloy ES, McCarthy GM. Eicosanoids, osteoarthritis, and crystal deposition diseases. Curr Opin Rheumatol. 2005;17(3):346-50.

2. Franceschi C, Bonafè M, Valensin S, Olivieri F, De Luca M, Ottaviani E, et al. Inflammaging: an evolutionary perspective on immunosenescence. Ann NY Acad Sci. 2000;908(1):244-54.

3. López-Otín C, Blasco MA, Partridge L, Serrano M, Kroemer G. The hallmarks of aging. Cell. 2013; 153(6):1194-217.

4. Brune K. Safety of anti-inflammatory treatment new ways of thinking. Rheumatol. 2004; 43(1):i16-20.

5. Raisz LG. Prostaglandins and bone: physiology and pathophysiology. 1999;7(4):419-21.

6. Martel-Pelletier J, Mineau F, Fahmi H, Laufer S, Reboul P, Boileau C, et al. Regulation of the expression of 5-lipoxygenase-activating protein/5lipoxygenase and the synthesis of leukotriene B4 in osteoarthritic chondrocytes: Role of transforming growth factor $\beta$ and eicosanoids. Arthritis Rheum. 2004;50(12):3925-33.

7. Khanapure SP, Garvey DS, Janero DR, Gordon Letts L. Eicosanoids in inflammation: biosynthesis, pharmacology, and therapeutic frontiers. Curr Top Med Chem. 2007;7(3):311-40.

8. Piomelli D. Arachidonic acid in cell signaling. Curr Opin Cell Biol. 1993;5(2):274-80.

9. Capdevila JH, Falck JR, Estabrook RW. Cytochrome P450 and the arachidonate cascade 1. FASEB J. 1992;6(2):731-6.

10. Tager AM, Luster AD. BLT1 and BLT2: the leukotriene B4 receptors. Prostaglan Leukot Essent Fatty Acids. 2003;69(2-3):123-34.

11. Janusz JM, Young PA, Scherz MW, Enzweiler K, Wu LI, Gan L, et al. New cyclooxygenase-2/5lipoxygenase inhibitors. 2. 7-tert-butyl-2, 3-dihydro3, 3-dimethylbenzofuran derivatives as gastrointestinal safe antiinflammatory and analgesic agents: variations of the dihydrobenzofuran ring. J Med Chem. 1998;41(7):1124-37.

12. Prete PE, Gurakar-Osborne A. The contribution of synovial fluid lipoproteins to the chronic synovitis of rheumatoid arthritis. Prostaglandins. 1997;54(4):689-98.

13. Martel-Pelletier J, Lajeunesse D, Reboul P, Pelletier JP. Therapeutic role of dual inhibitors of 5-LOX and COX, selective and non-selective non-steroidal antiinflammatory drugs. Ann Rheum Dis. 2003;62(6):501-9.

14. Martel-Pelletier J, Lajeunesse D, Pelletier JP. Etiopathogenesis of osteoarthritis. Arthritis and Allied Conditions. Ann Rheum Dis. 2005; 15:2199-226.

15. Warner TD, Mitchell JA. Cyclooxygenases: new forms, new inhibitors, and lessons from the clinic. FASEB J. 2004;18(7):790-804.

16. Bombardier C, Laine L, Reicin A, Shapiro D, Burgos-Vargas R, Davis B, et al. Comparison of upper gastrointestinal toxicity of rofecoxib and naproxen in patients with rheumatoid arthritis. N Engl J Med. 2000;343(21):1520-8.

17. Benito MJ, Veale DJ, FitzGerald O, van den Berg WB, Bresnihan B. Synovial tissue inflammation in early and late osteoarthritis. Ann Rheum Dis. 2005;64(9):1263-7.

18. Bertolini A, Ottani A, Sandrini M. Selective COX-2 inhibitors and dual acting anti-inflammatory drugs: critical remarks. Curr Med Chem. 2002;9(10):1033-43.

19. Vane JR. Inhibition of prostaglandin synthesis as a mechanism of action for aspirin-like drugs. Nature New Biol. 1971;231(25):232-5.

20. Rotondo S, Krauze-Brzósko K, Manarini S, Evangelista V, Cerletti C. Licofelone, an inhibitor of cyclooxygenase and 5-lipoxygenase, specifically 
inhibits cyclooxygenase-1-dependent platelet activation. Eur J Pharmacol. 2004;488(1-3):79-83.

21. Wallace JL, Chin BC. Inflammatory mediators in gastrointestinal defense and injury. Proc Soc Exp Biol Med. 1997;214(3):192-203.

22. Scheiman JM. Gastroduodenal safety of cyclooxygenase-2 inhibitors. Curr Pharm Des. 2003;9(27):2197-206.

23. Silverman ES, Drazen JM. The biology of 5lipoxygenase: function, structure, and regulatory mechanisms. Proc Assoc Am Physicians. 1999;111(6):525-36.

24. Ding C, Cicuttini F. Licofelone (Merckle). I Drugs. 2003;6(8):802-8.

25. Simon LS, Lanza FL, Lipsky PE, Hubbard RC, Talwalker S, Schwartz BD, et al. Preliminary study of the safety and efficacy of SC-58635, a novel cyclooxygenase 2 inhibitor: efficacy and safety in two placebo controlled trials in osteoarthritis and rheumatoid arthritis, and studies of gastrointestinal and platelet effects. Arthritis Rheumat. 1998;41(9):1591-602.

26. Cicero AF, Laghi L. Activity and potential role of licofelone in the management of osteoarthritis. Clin Interv Aging. 2007;2(1):73.

27. Parente L. Pros and cons of selective inhibition of cyclooxygenase-2 versus dual lipoxygenase/ cyclooxygenase inhibition: is two better than one?. J Rheumatol. 2001;28(11):2375-82.

28. Leval XD, Julémont F, Delarge J, Pirotte B, Dogné JM. New trends in dual 5-LOX/COX inhibition. Curr Med Chem. 2002;9(9):941-62.

29. Tries S, Neupert W, Laufer S. The mechanism of action of the new antiinflammatory compound ML3000: inhibition of 5-LOX and COX-1/2. Inflamm Res. 2002;51(3):135-43.

30. Jia QI. Generating and screening a natural product library for cyclooxygenase and lipoxygenase dual inhibitors. Stud Nat Prod Chem. 2003;29:643-718.

31. Alvaro-Gracia JM. Licofelone-clinical update on a novel LOX/COX inhibitor for the treatment of osteoarthritis. Rheumatology. 2004;43(1):i21-5.

32. Cicero AF, Derosa G, Gaddi A. Combined lipoxygenase/cyclo-oxygenase inhibition in the elderly. Drugs Aging. 2005;22(5):393-403.

33. Dyer RD, Connor DT. Dual inhibitors of prostaglandin and leukotriene biosynthesis. Curr Pharm Des. 1997;3:463-72.

34. Bellamy NI, Kirwan J, Boers M, Brooks P, Strand VI, Tugwell P, et al. Recommendations for a core set of outcome measures for future phase III clinical trials in knee, hip, and hand osteoarthritis. Consensus development at OMERACT III. J Rheumatol. 1997;24(4):799-802.

35. Henriksen M, Hansen JB, Klokker L, Bliddal H, Christensen R. Comparable effects of exercise and analgesics for pain secondary to knee osteoarthritis: a meta-analysis of trials included in Cochrane systematic reviews. J Comp Eff Res. 2016;5(4):417-31.
36. Juhl C, Lund H, Roos EM, Zhang W, Christensen R. A hierarchy of patient-reported outcomes for metaanalysis of knee osteoarthritis trials: empirical evidence from a survey of high impact journals. Arthritis. 2012.

37. Lee KP, Schotland M, Bacchetti P, Bero LA. Association of journal quality indicators with methodological quality of clinical research articles. JAMA. 2002;287(21):2805-8.

38. Raynauld JP, Martel-Pelletier J, Bias P, Laufer S, Haraoui B, Choquette D, et al. Protective effects of licofelone, a 5-lipoxygenase and cyclo-oxygenase inhibitor, versus naproxen on cartilage loss in knee osteoarthritis: a first multicentre clinical trial using quantitative MRI. Ann Rheum Dis. 2009;68(6):938-47.

39. Sprangers MA, de Regt EB, Andries F, van Agt HM, Bijl RV, de Boer JB, Foets M, Hoeymans N, Jacobs AE, Kempen GI, Miedema HS. Which chronic conditions are associated with better or poorer quality of life? J Clin Epidemiol. 2000;53(9):895-907.

40. Reginster JY. The prevalence and burden of arthritis. Rheumatology. 2002;41(1):3-6.

41. Davis MA. Epidemiology of osteoarthritis. Clin Geriatr Med. 1988;4(2):241-55.

42. Hilal G, Martel-Pelletier J, Pelletier JP, Ranger P, Lajeunesse D. Osteoblast like cells from human subchondral osteoarthritic bone demonstrate an altered phenotype in vitro: Possible role in subchondral bone sclerosis. Arthritis Rheum. 1998;41(5):891-9.

43. Smith WL, Garavito RM, DeWitt DL. Prostaglandin endoperoxide $\mathrm{H}$ synthases (cyclooxygenases)-1 and2. J Biol Chem. 1996;271(52):33157-60.

44. Huskisson EC, Berry H, Gishen P, Jubb RW, Whitehead J. Effects of antiinflammatory drugs on the progression of osteoarthritis of the knee. LINK Study Group. Longitudinal Investigation of Nonsteroidal Antiinflammatory Drugs in Knee Osteoarthritis. J Rheumatol. 1995;22(10):1941-6.

45. Martel-Pelletier J, Lajeunesse D, Pelletier JP. Etiopathogenesis of osteoarthritis. Arthritis and Allied Conditions. J Rheumatol. 2005;15:2199-226.

46. Yang K, Ma W, Liang H, Ouyang Q, Tang C, Lai L. Dynamic simulations on the arachidonic acid metabolic network. PLoS Comput Biol. 2007;3(3):e55.

47. He W, Pelletier JP, Martel-Pelletier J, Laufer S, Di Battista JA. Synthesis of interleukin 1beta, tumor necrosis factor-alpha, and interstitial collagenase (MMP-1) is eicosanoid dependent in human osteoarthritis synovial membrane explants: interactions with antiinflammatory cytokines. J Rheumatol. 2002;29(3):546-53.

48. Cheng S, Afif H, Martel-Pelletier J, Pelletier JP, Li $\mathrm{X}$, Farrajota $\mathrm{K}$, et al. Activation of peroxisome proliferator-activated receptor $\gamma$ inhibits interleukin$1 \beta$-induced membrane-associated prostaglandin E2 synthase-1 expression in human synovial fibroblasts 
by interfering with Egr-1. J Biol Chem. 2004; 279(21):22057-65.

49. Martel-Pelletier J, Mineau F, Fahmi H, Laufer S, Reboul P, Boileau C, et al. Regulation of the expression of 5-lipoxygenase-activating protein/5lipoxygenase and the synthesis of leukotriene B4 in osteoarthritic chondrocytes: Role of transforming growth factor $\beta$ and eicosanoids. Arthritis Rheum. 2004;50(12):3925-33.

50. Marcouiller P, Pelletier JP, Guévremont M, MartelPelletier J, Ranger P, Laufer S, et al. Leukotriene and prostaglandin synthesis pathways in osteoarthritic synovial membranes: regulating factors for interleukin 1beta synthesis. J Rheumatol. 2005;32(4): 704-12.

51. Paredes Y, Massicotte F, Pelletier JP, MartelPelletier J, Laufer S, Lajeunesse D. Study of the role of leukotriene B4 in abnormal function of human subchondral osteoarthritis osteoblasts: Effects of cyclooxygenase and/or 5-lipoxygenase inhibition. Arthritis Rheum. 2002;46(7):1804-12.

52. Laufer S. Discovery and development of ML3000. Inflammopharmacol. 2001;9(1):101-12.

53. Pelletier JP, Martel-Pelletier J, Abramson SB. Osteoarthritis, an inflammatory disease: potential implication for the selection of new therapeutic targets. Arthritis Rheum. 2001;44(6):1237-47.

54. Reginster JY. The prevalence and burden of arthritis. Rheumatology. 2002; 41(1):3-6.

55. Blanco FJ, Buchner A, Bias P, Lammerich A, Schulz U. Licofelone, an inhibitor of COX-1, COX-2 and 5LOX, is as effective as naproxen and shows improved safety during 12 months of treatment in patients with osteoarthritis of the knee. Ann Rheum Dis. 2003;62:262-5.

56. Raynauld JP, Martel-Pelletier J, Bias P, Laufer S, Haraoui B, Choquette D, et al. Protective effects of licofelone, a 5-lipoxygenase and cyclo-oxygenase inhibitor, versus naproxen on cartilage loss in knee osteoarthritis: a first multicentre clinical trial using quantitative MRI. Ann Rheum Dis. 2009;68(6):93847.

57. Aigner T, Hemmel M, Neureiter D, Gebhard PM, Zeiler G, Kirchner T, et al. Apoptotic cell death is not a widespread phenomenon in normal aging and osteoarthritic human articular knee cartilage: a study of proliferation, programmed cell death (apoptosis), and viability of chondrocytes in normal and osteoarthritic human knee cartilage. Arthritis Rheum. 2001;44(6):1304-12.

58. Burr DB, Schaffler MB. The involvement of subchondral mineralized tissues in osteoarthrosis: quantitative microscopic evidence. Microsc Res Tech. 1997;37(4):343-57.

59. Rodier F, Campisi J. Four faces of cellular senescenceFour faces of senescence. J Cell Biol. 2011;192(4):547-56.
60. Brophy RH, Rai MF, Zhang Z, Torgomyan A, Sandell LJ. Molecular analysis of age and sex-related gene expression in meniscal tears with and without a concomitant anterior cruciate ligament tear. The J Bone Joint Surg. 2012;94(5):385.

61. Greene MA, Loeser RF. Aging-related inflammation in osteoarthritis. Osteoarthr Cartil. 2015;23(11): 1966-71.

62. Raynauld JP, Martel-Pelletier J, Bias P, Laufer S, Haraoui B, Choquette D, et al. Protective effects of licofelone, a 5-lipoxygenase and cyclo-oxygenase inhibitor, versus naproxen on cartilage loss in knee osteoarthritis: a first multicentre clinical trial using quantitative MRI. Ann Rheum Dis. 2009;68(6):93847.

63. Parente L. Pros and cons of selective inhibition of cyclooxygenase-2 versus dual lipoxygenase/cyclooxygenase inhibition: is two better than one?. J Rheumatol. 2001;28(11):2375-82.

64. Freund A, Orjalo AV, Desprez PY, Campisi J. Inflammatory networks during cellular senescence: causes and consequences. Trends Mol Med. 2010; 16(5):238-46.

65. Sohn DH, Sokolove J, Sharpe O, Erhart JC, Chandra $\mathrm{PE}$, Lahey LJ, et al. Plasma proteins present in osteoarthritic synovial fluid can stimulate cytokine production via Toll-like receptor 4. Arthritis Res Ther. 2012;14(1):1-3.

66. Alaaeddine N, Olee T, Hashimoto S, CreightonAchermann L, Lotz M. Production of the chemokine RANTES by articular chondrocytes and role in cartilage degradation. Arthritis Rheum. 2001;44(7): 1633-43.

67. Li WQ, Dehnade F, Zafarullah M. Oncostatin Minduced matrix metalloproteinase and tissue inhibitor of metalloproteinase-3 genes expression in chondrocytes requires Janus kinase/STAT signaling pathway. J Immun. 2001;166(5):3491-8.

68. Loeser RF, Goldring SR, Scanzello CR, Goldring MB. Osteoarthritis: a disease of the joint as an organ. Arthritis Rheum. 2012;64(6):1697.

69. Freund A, Patil CK, Campisi J. p38MAPK is a novel DNA damage response independent regulator of the senescence associated secretory phenotype. EMBO J. 2011;30(8):1536-48.

70. Reijman M, Bierma-Zeinstra SM, Pols HA, Koes BW, Stricker BH, Hazes JM. Is there an association between the use of different types of nonsteroidal antiinflammatory drugs and radiologic progression of osteoarthritis? The rotterdam study. Arthritis Rheum. 2005;52(10):3137-42.

Cite this article as: Vinod KP. Licofelone in osteoarthritis: is this the awaited drug? A systematic review. Int J Basic Clin Pharmacol 2021;10:564-71. 